\title{
SISTEM BIOFILTRASI AIR RAWA GAMBUT DAN PENGARUH FILTRASI TERHADAP pH, BOD, COD, TSS DAN ASAM HUMAT AIR RAWA GAMBUT DENGAN ADANYA PENAMBAHAN KARBON
}

\author{
Hasnirwan, Hermansyah Aziz, Rhieka Whulanda \\ Jurusan Kimia FMIPA Universitas Andalas, Padang
}

\begin{abstract}
The research about bio-filtration of peat water using paddy chaff coated by carbon as filter biomaterial has been conducted. Iodimetry titration method was selected for determination of BOD and COD concentration, while gravimetry method and UV/Vis spectrophotometry is used to determinate TSS and humic acid containing in sample. The results of filtration with bio-filter lock up this paddy able to reduce organic compounds in peat water. The existence of coating carbon causing of BOD $22.37 \mathrm{mg} / \mathrm{L}$ (without carbon $27.73 \mathrm{mg} / \mathrm{L}$ ), COD $54.30 \mathrm{mg} / \mathrm{L}$ (without carbon 86.02 $\mathrm{mg} / \mathrm{L}$ ), TSS $120 \mathrm{mg} / \mathrm{L}$ (without carbon $155 \mathrm{mg} / \mathrm{L}$ ) concentration was decreasing, especially at the third step of filtration.
\end{abstract}

Keywords : peat water, biofiltration, biomass

\section{DAFTAR PUSTAKA}

1. C. T. Sutrisno, dkk, Teknologi Penyediaan Air Bersih, Rineka Cipta, Jakarta, 2004, 65 dan 73-77.

2. M. M. Sutejo, A. G Kartasapoetra Pengantar Ilmu Tanah, Rineka Cipta, Jakarta, 2005, 37-39.

3. N. Hakim, dkk, Dasar- Dasar Ilmu Tanah. Universitas Lampung, Jakarta, 1986, 75-76.

4. A. Siswoyo, Teori Analisis Air, AKA MIGAS Pusat Pengembangan Tenaga Perminyakan dan Gas Bumi, Cepu, 1998, 18-25.

5. P. Ginting, Sistem Pengolahan Lingkungan dan Limbah Industri, Xrana Widya, Bandung, 2007, 147-160.

6. M. Noor, Lahan Rawa, PT. Raharja Grafindo Persada, Jakarta, 2004, 120-124.

7. O. Untung, Menjernihkan Air Kotor, Puspa Swara, Jakarta, 2005, 10-13.

8. F. Riyanti, L. H. Poedji, Studi Pengolahan Air Rawa dengan Menggunakan Arang dan Daun Serai (Andropogen Nardus L). Prosiding Seminar PPD Forum HEDS 2004 Bidang MIPA, Palembang, 374-381, (2004).

9. G. Alaerts, S. Santika, Metoda Penelitian Air. Usaha Nasional, Surabaya, 1987, 224230.
10. P. Mas'ud, Telaah Kesuburan Tanah. Cetakan kesepuluh, Penerbit Angkasa, Bandung, 1993.

11. M. Karlsson, et al., Determination of Nitrite In Municiple Waste by UV Spectroscopy, J. Anal. Chem. Acta, 312: 107-113, (1995).

12. H. Aziz, A. Alif, dan Safni, Proses Primer dalam Fotokimia, FMIPA UNAND, Padang, 1995, 43-50.

13. A. M. Braun, M. T. Maurette and E. Oliveros, Photochemical Technology, Willey, Chichester, 1991, 1-93, 70-77.

14. F. J. Stevenson, Geochemistry of Soil Humic Substances, Humic Subtances in Soil, Sediment and Water, John Willey and Sons, USA, 1951, 13-52.

15. P. W. Atkins, Kimia Fisika, Erlangga, Jakarta, 1997.

16. R. D. Haworth, The Chemical Nature of Humic Acid, Soil Science, Vol 3 No.1, William and Willkin Co. USA, 1951, 7179.

17. S. Ketaren dan S. Wijayandi, Pemurnian Minyak. Departemen Teknologi Hasil Pertanian, IPB, Bogor,1974.

18. Isdahartati, Pemenfaatan Arang Tempurung Kelapa Sebagai Biomaterial Penyerap Ion Logam Besi dan Cromium, Tesis Universitas Negeri Padang, 2000. 
19. http://www.Antara.co.id/arc/2006/5/12/ Pencemaran di Batang Arau Padang Semakin Parah. 1-2.
20. http://www. Antara.co.id/arc/2008/3/ Removal of Stryrene From Waste Gas Stream Using a Biofilter. 